\title{
Synthesis of New 1,2,3-Triazolo-naphthalimide/phthalimide Conjugates via 'Click' Reaction: DNA Intercalation and Cytotoxic Studies
}

\author{
Nagula Shankaraiah, ${ }^{*, a}$ Niggula P. Kumar, ${ }^{a}$ Ramya Tokala, ${ }^{a}$ Bulusu S. Gayatri, ${ }^{a}$ \\ Venu Talla ${ }^{b}$ and Leonardo S. Santos ${ }^{\circledR} *, c$ \\ ${ }^{a}$ Department of Medicinal Chemistry, \\ National Institute of Pharmaceutical Education and Research (NIPER), \\ 500037 Hyderabad, India \\ ${ }^{b}$ Department of Pharmacology and Toxicology, \\ National Institute of Pharmaceutical Education and Research (NIPER), \\ 500037 Hyderabad, India \\ ${ }^{c}$ Laboratory of Asymmetric Synthesis, Chemistry Institute of Natural Resources, \\ University of Talca, P.O. Box 747, Talca, Chile
}

\begin{abstract}
Cancer is a complex disease which involves abnormalities of multiple cellular pathways. Current chemotherapeutic drugs are mainly designed to target the DNA and cell division. Therefore, in the present study, we have synthesized a new series of 1,2,3-triazolo-naphthalimide/phthalimide conjugates and evaluated their in vitro cytotoxicity against selected human cancer cells. Among the tested compounds, one of them displayed notable cytotoxic activity against A549 lung cancer cells with an $\mathrm{IC}_{50}$ (half maximal inhibitory concentration) value of $7.6 \pm 0.78 \mu \mathrm{M}$. To determine the effect of this compound on cell viability, acridine orange/ethidium bromide (AO/EB) and 4',6-diamidino-2-phenylindole (DAPI) staining studies were performed. These apoptotic features were clearly indicating that the compound inhibited cell proliferation by apoptosis. Further, relative viscosity measurements and molecular docking studies with the most three active compounds indicated that these new compounds bind to DNA by intercalation.
\end{abstract}

Keywords: naphthalimides, 1,2,3-triazoles, DNA intercalation, click reaction

\section{Introduction}

Cancer is considered as one of the lethal diseases worldwide and the incidence of cancer has been rising in major regions of the world with predicted substantive increase to 19.3 million by the year $2025 .{ }^{1}$ Although the scientific advances focused on finding exact pathophysiology of the disease and tremendous efforts have been made on early detection of cancer, the overall mortality rate has not declined. ${ }^{2}$ In this connection, there is an immense need to design and synthesize effective new chemotherapeutic agents to combat cancer. Due to complexity with redundant and robust biological networks, cancer cells exhibits uncontrolled cell proliferation, metastasis and also become resistant to apoptotic signals. ${ }^{3}$ As cancer cells are

*e-mail: shankarnbs@gmail.com, shankar@niperhyd.ac.in; 1ssantos@utalca.cl highly proliferative tissues, the DNA becomes one of the most promising biological targets to develop antitumor agents. ${ }^{4}$ DNA replication has an invaluable role in cancer cell division, hence polycyclic planar molecules such as doxorubicin, acridines, anthraquinones, distamycins, naphthalimides and phenanthrene derivatives are well recognized as DNA targeting antitumor agents. ${ }^{5}$

Naphthalimides are aromatic heterocycles with profound biological significance and they serve as core scaffold for many anti-tumor, anti-inflammatory, antidepressant, antiprotozoal and antiviral compounds. ${ }^{6}$ Planarity is the most important prerequisite for DNA intercalation and also facilitates embedding into DNA base pairs. ${ }^{7}$ Owing to their tricyclic planar structure, naphthalimide is primarily responsible for its intercalation with DNA to perturb the cellular events, thereby prevents cancer cell divison. ${ }^{8}$ Representative examples of naphthalimide based molecules such as mononaphthalimide (i.e., amonafide, Figure 1) and 
bisnaphthalimides (i.e., elinafide) have reached the clinical trials, but due to central neurotoxicity and limited efficacy in solid tumors, the clinical development was regrettably terminated. ${ }^{9}$ However, their structural modification lead to potent antitumor agents with improved efficacy and toxicological profile. ${ }^{10}$ In 2005 , Cholody et al. ${ }^{11}$ investigated asymmetrical bi-functional antitumor agents by conjugating imidazoacridone moiety to the naphthalimide core. This imidazoacridone linked nitro naphthalimide conjugate efficiently interacted with DNA and induction of apoptosis. Moreover, naphthalimides conjugated with pyrrolo[2,1-c][1,4]benzodiazepines through a pyrazine moiety with an alkane spacer has also been proved to increase the DNA binding affinity and anticancer activity. ${ }^{12}$

In the dimeric form of intercalators such as bisphenanthridines, bisnaphthalimides and bisphenazine carboxamides have also displayed potent antitumor potential. The promising in vivo activities of drugs such as bisnafide (bisnaphthalimide) ${ }^{13}$ and WP631 (bisanthracyclines) ${ }^{14}$ have stimulated to search for novel bifunctional DNA ligands. The basic principle behind the design of dimers is to enhance sequence recognition and DNA binding affinity. However, in some instances, the second chromophore does not play the role of intercalator, instead it can serve as a hook to trap DNA binding proteins and cofactors.

On the other hand, 1,2,3-triazoles are considered as privileged building blocks in the context of bioconjugates. They are highly stable under basic and acid hydrolysis including oxidative and reductive conditions. Moreover, this heterocycle is the bioisostere of amide and is capable of interacting with biomolecular targets through hydrogen-bonding. ${ }^{15}$ This scaffold is well recognized for their multitude of biological properties such as anti-malarial, anti-leishmanial, anti-trypanosomal, anti-allergic, antifungal, antibacterial, antitubercular, antiHIV, anticancer, antimalarial and antiviral properties. ${ }^{16}$ Fascinatingly, it can interact with DNA and also acts as a supporting motif for DNA targeting drugs. ${ }^{17}$ 1,2,3-Triazoles tethered to various bioactive molecules such as $\beta$-carbolines and phenanthrenes also resulted in enhanced antitumor potential through effective DNA intercalation. ${ }^{18}$ Quian and co-workers ${ }^{19}$ have reported that 1,8-naphthalimide substituted triazole derivatives could enhance the cytotoxicity and improves the affinity towards calf thymus (CT)-DNA. The enhanced cytotoxicity has been attributed to the presence of triazole nucleus. Prompted by the above reports, in the present study we have designed and synthesized a library of 1,2,3-triazolo based naphthalimide/phthalimide conjugates and evaluated their in vitro cytotoxicity and DNA intercalating capabilities.

The $\mathrm{Cu}^{\mathrm{I}}$-catalyzed 1,3-dipolar cycloaddition of azide and alkynes (CuAAC) or 'click chemistry' can rapidly yield bioactive molecules linked through 1,2,3-triazole. ${ }^{20} \mathrm{Cu}^{\mathrm{I}}$ catalyst allows the cycloaddition to provide 1,4-regioselectivity in 1,2,3-triazole ring formation. Currently, the most widely used reaction conditions for the 1,4-regiospecific method is the use of an organic solvent, such as $t-\mathrm{BuOH}$ or $\mathrm{CH}_{2} \mathrm{Cl}_{2}$, water, $\mathrm{CuSO}_{4} \cdot 5 \mathrm{H}_{2} \mathrm{O}$ and sodium ascorbate. Despite the numerous advantages of the CuAAC reactions, the organic azides employed therein are hazardous and their handling is very risky. ${ }^{21}$ In this context, efficient protocols that eliminate the handling of organic azides are highly preferable. ${ }^{22}$ In continuation of our earlier efforts dedicated to triazole chemistry towards the synthesis of diverse bioactive molecules, ${ }^{23}$ recently, we have also reported a novel, simple and efficient bis[(tetrabutylammonium)di- $\mu$-iododiiododicuprate(I)] catalyzed one-pot, three component 1,3-dipolar cycloaddition of alkyl/benzyl bromides with

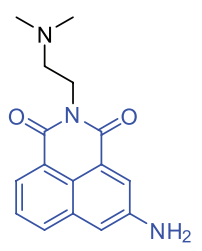

Amonafide

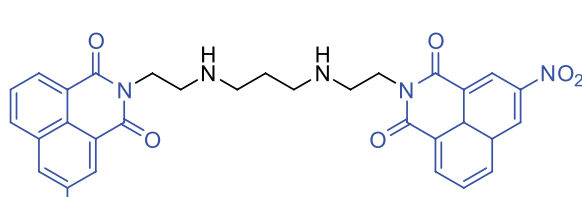

Elinafide

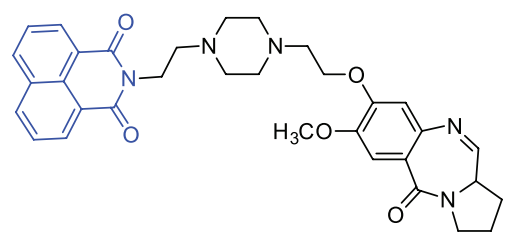

Pyrrolo[2,1-c][1,4]benzodiazepines linked naphthalimide
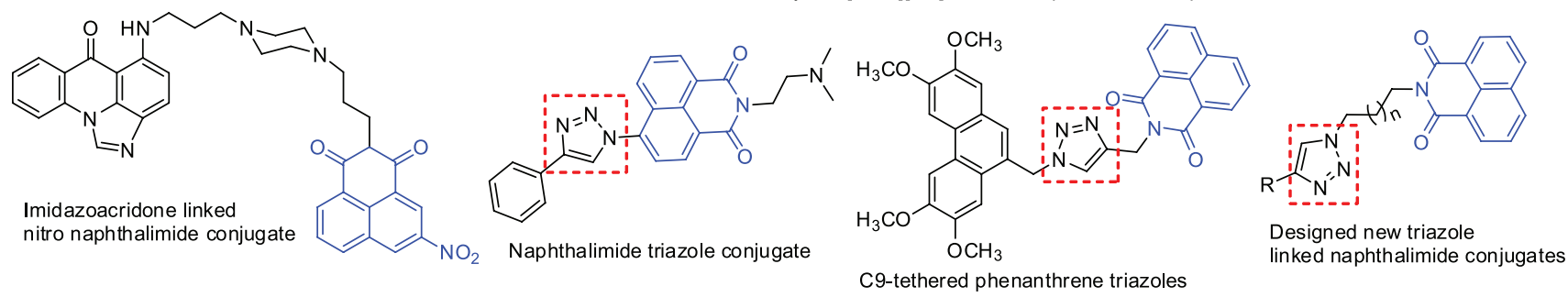

linked naphthalimide conjugates

C9-tethered phenanthrene triazoles

Figure 1. Structures of naphthalimide, triazole containing derivatives and newly designed 1,2,3-triazolo-naphthalimide conjugates. 
sodium azide and alkynes for the regioselective synthesis of 1,4-disubstituted 1,2,3-triazoles in water. ${ }^{24}$ Herein we have applied this efficient protocol for the synthesis of a variety of diversely substituted 1,2,3-triazolo-naphthalimide/ phthalimide conjugates. The advantages of this onepot reaction are the use of water as solvent and in situ generation of azides from alkyl halides and thus handling of hazardous azides is avoided. The newly synthesized compounds were evaluated for their in vitro cytotoxicity and DNA binding affinity.

\section{Results and Discussion}

\section{Chemistry}

The syntheses of 1,2,3-triazole based naphthalimide/ phthalimide conjugates $\mathbf{6 a - x}$, and $\mathbf{7 a - c}$ have been achieved by a two-step reaction as depicted in Scheme 1. Initially, alkylation followed by one-pot three component reaction affords the desired 1,4-disubstituted-1,2,3-triazoles in excellent yields. At first, 1,8-naphthalimide (1) and phthalimide (2) were alkylated by using various dibromo alkane spacers (like 1,3-dibromo propane, 1,4-dibromo butane, 1,5-dibromo pentane and 1,6-dibromo hexane) in the presence of $\mathrm{K}_{2} \mathrm{CO}_{3}$ and dimethylformamide (DMF) was used as solvent, which resulted in the formation of various $N$-alkylated naphthalimides $\mathbf{3 a - c}$ and phthalimide $\mathbf{4}$ precursors. Simultaneously, various $N$ - and $O$-linked alkyne partners were also prepared by propargylation of substituted amines and phenols, respectively. Finally, onepot three component 1,3-dipolar cycloaddition reaction was performed with various synthesized alkyne partners $5 \mathbf{a}-\mathbf{i}$ to provide the corresponding 1,4-disubstituted 1,2,3-triazoles. Bis[(tetrabutylammonium)di- $\mu$-iodo-diiododicuprate(I)] was used as a $\mathrm{Cu}^{\mathrm{I}}$ catalyst to promote this reaction in water as reaction medium. The catalyst enhanced the water solubility of the alkyl halides. In the presence of sodium azide, naphthalimide and phthalimide azides are formed in situ from $N$-alkylated naphthalimides and phthalimides, respectively. Finally, different alkyne partners undergo $\mathrm{Cu}^{\mathrm{I}}$-catalyzed azide-alkyne cycloaddition (CuAAC) reaction with various naphthalimide/phthalimide azides to give diverse 1,2,3-triazolo-naphthalimide/phthalimide conjugates $\mathbf{6 a - x}$ and $\mathbf{7 a - c}$.

\section{Pharmacology}

\section{Cytotoxic activity}

The newly synthesized 1,2,3-triazolo-naphthalimide/ phthalimide conjugates were evaluated for their in vitro cytotoxicity against different cancer cell lines such as lung (A549), prostate (PC-3), breast (MCF-7), cervical cancer (HeLa) and a normal cell line (RPE1) by using 3-(4,5-dimethylthiazol-2-yl)-2,5-diphenyltetrazolium bromide (MTT) assay. ${ }^{25}$ Cell lines were treated with the compounds at $50 \mu \mathrm{M}$ concentration for $48 \mathrm{~h}$ and growth inhibition percentage was noted. Among them, some of the representative compounds $\mathbf{6 b}, \mathbf{6 c}, \mathbf{6 d}, \mathbf{6 j}, \mathbf{6 k}, \mathbf{6 p}, \mathbf{6 u}$, $\mathbf{6 v}$ and $7 \mathbf{a}$ displayed cytotoxicity above $50 \%$ at $50 \mu \mathrm{M}$ and were selected to screen for the dose dependent responses and $\mathrm{IC}_{50}$ (concentration required to inhibit $50 \%$ of the tumor cells) values for these active compounds were reported. The $\mathrm{IC}_{50}(\mu \mathrm{M})$ values of the active compounds and the reference drug doxorubicin are listed in Table 1.

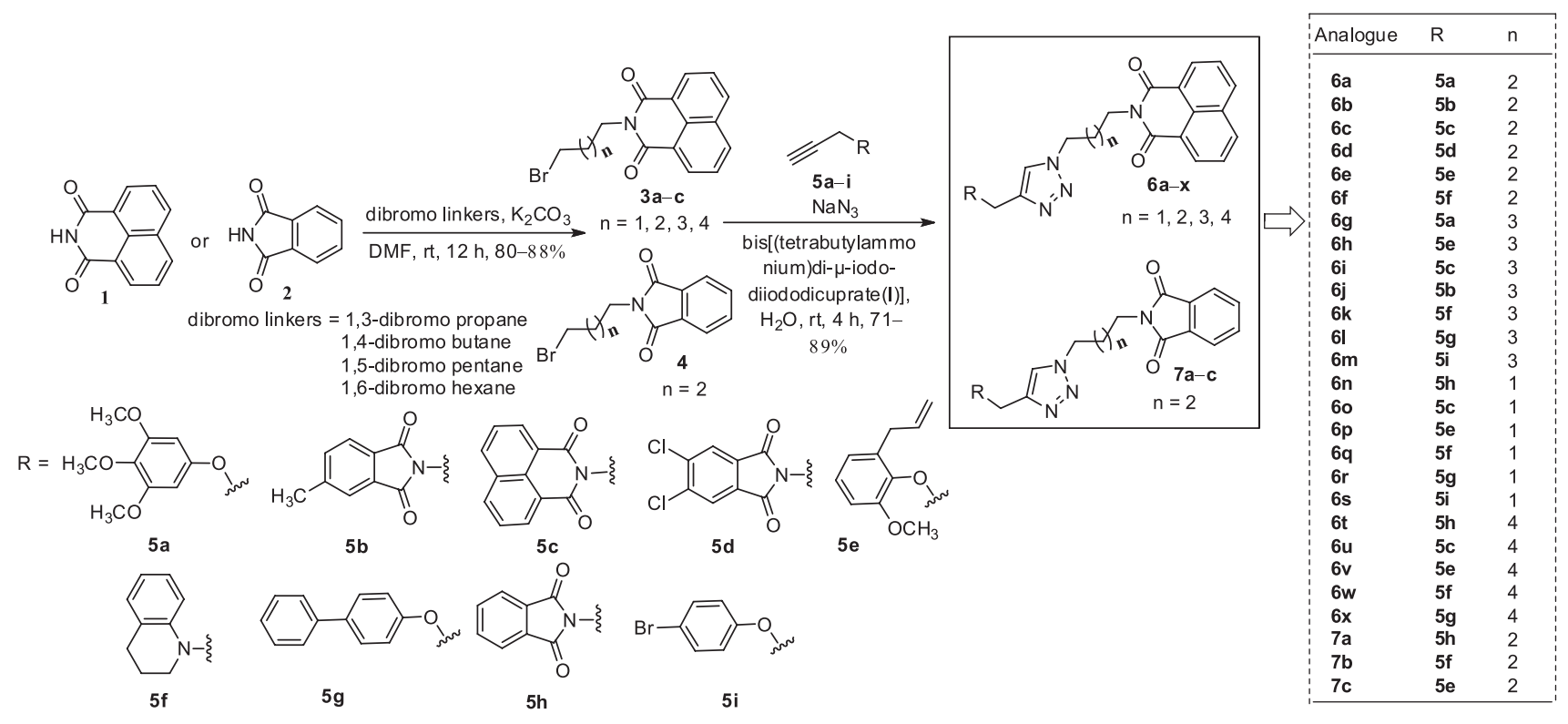

Scheme 1. Synthetic strategy for the preparation of 1,2,3-triazolo-naphthalimide/phthalimide conjugates 6a-x, 7a-c. 
It is observed from the cytotoxicity results that derivatives containing planar phthalimide or naphthalimide nucleus in their structures showed moderate cytotoxicity and compound $\mathbf{6 c}$, possessing naphthalimide and triazole cores linked through a 4 carbon linker, displayed good cytotoxic activity on A549 lung cancer cells with an $\mathrm{IC}_{50}$ value of $7.6 \pm 0.78 \mu \mathrm{M}$ (Table 1). Some of the tested compounds $\mathbf{6 d}, \mathbf{6 k}, \mathbf{6 u}$, and 7a displayed moderate cytotoxicity against the cervical and prostate cancer cells. From careful analysis of $\mathrm{IC}_{50}$ values, it was observed that most of the dimers containing phthalimide or naphthalimide scaffolds linked through various triazole linkers were adequately active against the cancer cell lines. Further, cytotoxicity of the most active compounds was also tested on normal cell line (RPE1). Interestingly, most of the compounds were nontoxic to the normal cells and the most active compound $\mathbf{6 c}$ showed selectivity index (ratio of cytotoxicity of normal cell line to that of cancer cells) of 6 folds approximately. Based on the observed cytotoxicity results, one of the active compounds $\mathbf{6 c}$ was taken-up for examining the mechanism of cancer cell growth inhibition through cell staining techniques. Additionally, to prove the DNA interaction of these planar molecules, we have also investigated the relative viscosity alterations of these new molecules $\mathbf{6 c}, \mathbf{6 d}$, 6p and performed molecular docking studies to explain the possible mode of interaction with DNA.

\section{Acridine orange/ethidium bromide (AO/EB) staining}

Acridine orange/ethidium bromide (AO/EB) fluorescent staining assay was performed to differentiate the live, apoptotic, and necrotic cells. ${ }^{26} \mathrm{AO}$ penetrates the healthy cells and stains the nuclei green, whereas EB enters only into membrane disintegrated cells and stain the nucleus red.
It can be observed from Figure 2 that the green color of the control cells is due to their normal morphology. From the Figure, it was clear that the cell viability is decreased in concentration dependent manner. Fluorescence microscopic images of the cells treated with $20 \mu \mathrm{M}$ of compound $\mathbf{6 c}$ clearly showed the altered morphological characteristics, suggesting that the compound $\mathbf{6 c}$ induced cell death in A549 cells.

\section{DAPI staining}

DAPI (4',6-diamidino-2-phenylindole) is a fluorescent stain that effectively binds to A-T rich regions in DNA and reveals the nuclear damage. DAPI permeates the live cell membrane with less efficiency. Therefore, the intensity of staining in live cells is lesser, whereas apoptotic cells are stained bright due to the presence of condensed nucleus. Therefore, we have examined the effect of compound $\mathbf{6 c}$ on A549 cells by using DAPI staining. ${ }^{27}$ This technique differentiates dead and live cells based on nuclear morphology. DAPI stains the nucleus bright blue by forming a fluorescent complex with chromatin. As observed from Figure 3, the nuclear structure of control cells was intact whereas compound $\mathbf{6 c}$ treated A549 cells exhibited condensed nuclei, indicating the characteristic features of cancer cell death.

\section{Relative viscosity study}

Relative viscosity studies are helpful to predict the interactions of tested compounds with DNA. These studies were performed for the active compounds $\mathbf{6 c}, \mathbf{6 d}$, and $\mathbf{6 p}$ along with ethidium bromide, Hoechst 33258, and doxorubicin to study their interactions with DNA by measuring the changes in relative viscosity. Intercalation

Table 1. Cytotoxic activity of some of the 1,2,3-triazolo based naphthalimide/phthalimide conjugates

\begin{tabular}{|c|c|c|c|c|c|}
\hline \multirow{2}{*}{ Compound } & \multicolumn{5}{|c|}{$\mathrm{IC}_{50}{ }^{\mathrm{a}} / \mu \mathrm{M}$} \\
\hline & $\mathrm{A} 549^{\mathrm{b}}$ & $\mathrm{MCF}-7^{\mathrm{c}}$ & $\mathrm{PC}-3^{\mathrm{d}}$ & $\mathrm{HeLa}^{\mathrm{e}}$ & $\mathrm{RPE}^{\mathrm{f}}$ \\
\hline $6 \mathbf{b}$ & $21.3 \pm 1.43$ & $>50$ & $>50$ & $>50$ & $72.7 \pm 0.88$ \\
\hline $6 c$ & $7.6 \pm 0.78$ & $>50$ & $>50$ & $>50$ & $46.5 \pm 1.31$ \\
\hline 6d & $17.0 \pm 1.39$ & $>50$ & $>50$ & $44.8 \pm 2.34$ & $67.9 \pm 0.57$ \\
\hline $6 \mathbf{j}$ & $27.9 \pm 1.53$ & $>50$ & $>50$ & $>50$ & - \\
\hline $6 k$ & $24.1 \pm 0.52$ & $>50$ & $>50$ & $33.6 \pm 3.85$ & $89.1 \pm 0.04$ \\
\hline $6 p$ & $19.1 \pm 1.26$ & $>50$ & $>50$ & $>50$ & $83.6 \pm 0.47$ \\
\hline $6 u$ & $>50$ & $>50$ & $34.2 \pm 2.65$ & $>50$ & - \\
\hline $6 v$ & $41.7 \pm 2.79$ & $>50$ & $>50$ & $>50$ & - \\
\hline $7 \mathbf{a}$ & $25.1 \pm 1.83$ & $>50$ & $45.1 \pm 3.28$ & $>50$ & - \\
\hline Doxorubicin $^{\mathrm{g}}$ & $1.88 \pm 0.56$ & $10.9 \pm 1.76$ & $0.08 \pm 0.001$ & $0.36 \pm 0.02$ & $13.9 \pm 1.10$ \\
\hline
\end{tabular}

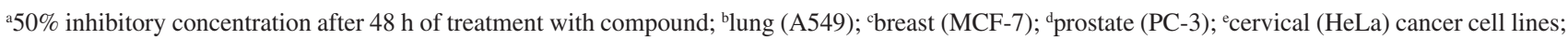
fnormal retinal cells (RPE1); ${ }^{g}$ reference compound. 


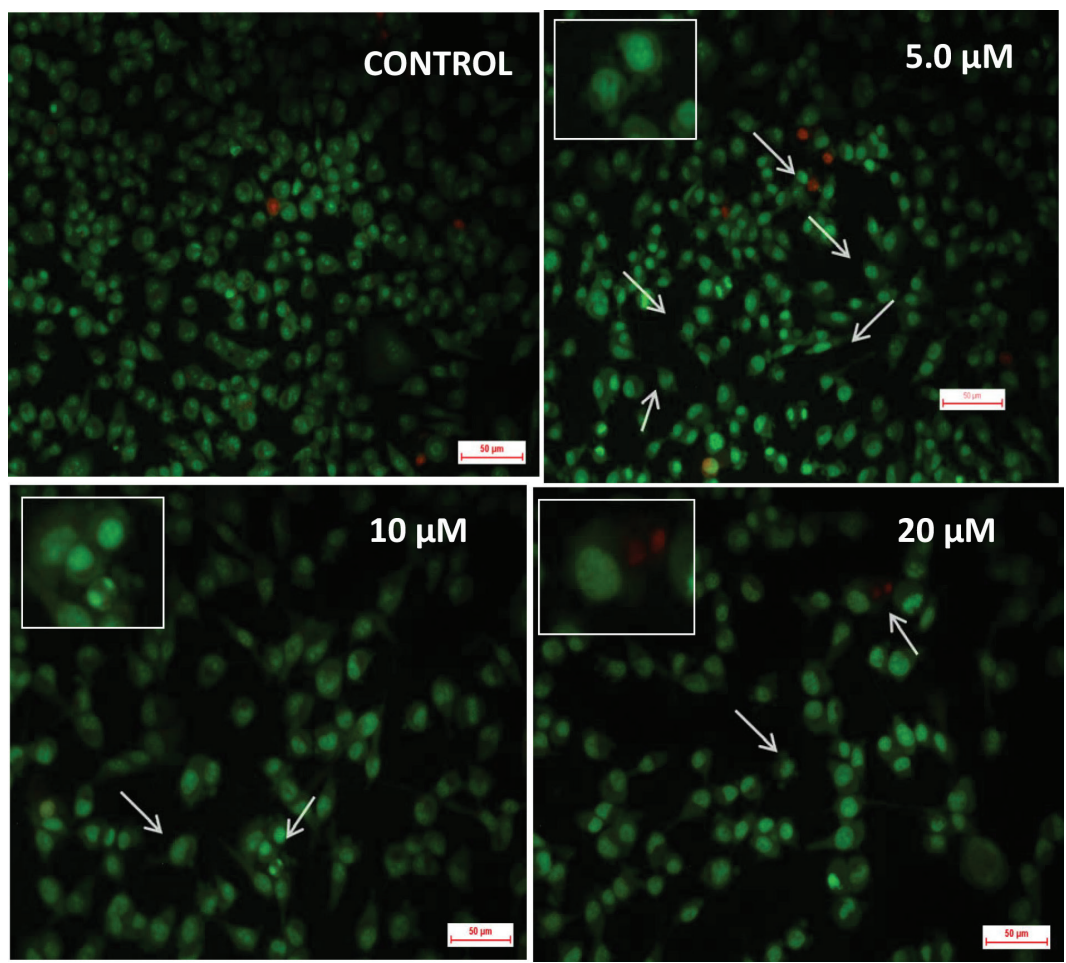

Figure 2. AO/EB staining in A549 cells treated with various concentrations of compound $\mathbf{6 c}$. Apoptotic features and dead cells were observed.

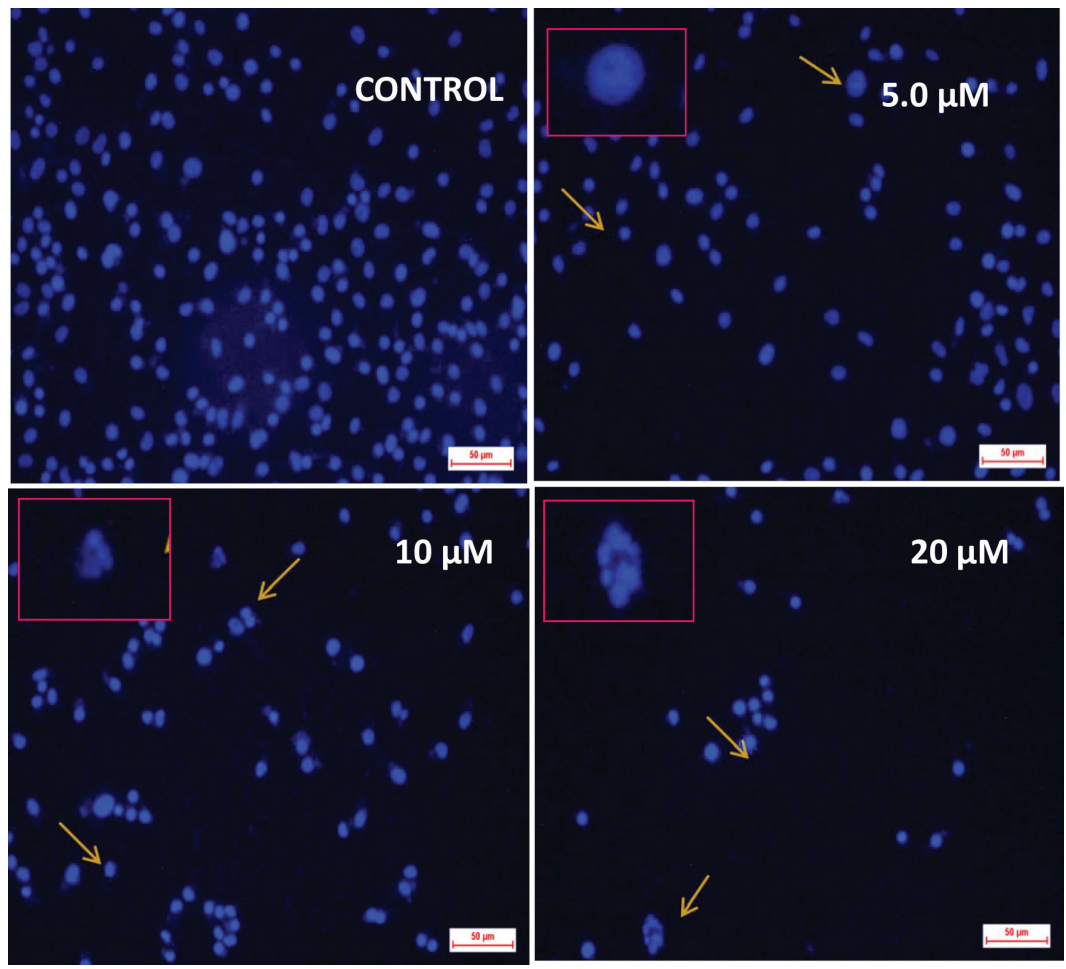

Figure 3. DAPI staining: A549 cells treated with compound $\mathbf{6 c}$ and stained with DAPI. The images were captured with fluorescence microscope with a DAPI filter.

of small molecules like ethidium bromide between the base pairs of DNA leads to the substantial increase in viscosity; whereas a minimal change in viscosity is observed with groove binders like Hoechst 33258.
Doxorubicin is a well-known intercalator, which shows a rapid increase in viscosity down the concentration. The addition of these compounds $\mathbf{6 c}, \mathbf{6 d}$, and $\mathbf{6 p}$ to CT-DNA results in a gradual increase of viscosity in concentration 
depending manner. This infers that the naphthalimidetriazole congeners bind to DNA by intercalation. The Figure 4 shows a graph plotted between concentration (compound/CT-DNA) and viscosity $\left(\left(\eta / \eta_{0}\right)^{1 / 3}\right)$ on $x$ and $\mathrm{y}$-axis, respectively, with ethidium bromide, Hoechst 33258 and doxorubicin as standards.

\section{Molecular docking}

Molecular docking studies were performed for the most active compounds $\mathbf{6 c}, \mathbf{6 d}$ and $\mathbf{6 p}$ using duplex DNA (PDB: 209D) ${ }^{28}$ by XP Glide 7.4 (Schrödinger 2017-1) ${ }^{29}$ with default settings (Figure 5). The perfect planar insertion of the naphthalimide ring between G-C base pairs in the site of intercalation was observed. Further, the triazole and alkyl chain acts as the linker and orients the complementary substitution (naphthalimide in $\mathbf{6} \mathbf{c}$ and $\mathbf{6 p}$ and phthalimide moiety in 6p) into the minor groove. Moreover, the docked poses were stabilized by $\pi-\pi$ stacking interactions of naphthalimide ring and hydrogen-bonding interactions between the carbonyl oxygens of naphthalimide towards base pairs of DNA in the minor groove. Thereby, dual mode of binding with DNA (DNA intercalation and minor groove binding) was observed with these compounds supporting their efficacy as DNA interacting agents. These results

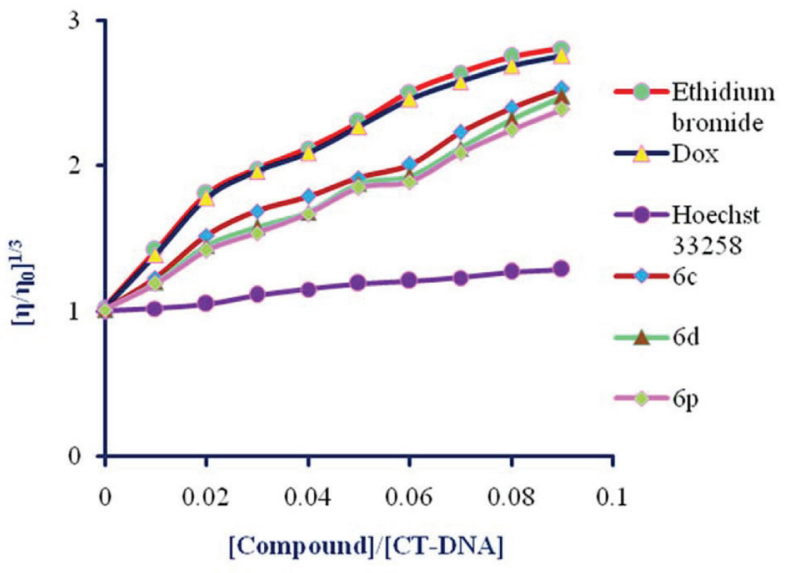

Figure 4. Graphical representation of relative viscosity studies using compounds $\mathbf{6 c}, \mathbf{6 d}$ and $\mathbf{6} \mathbf{p}$ with doxorubicin, Hoechst-33258, and ethidium bromide as reference standards.

were compatible with in vitro cytotoxicity and relative viscosity studies.

\section{Conclusions}

In the present work, a new series of 1,2,3-triazolonaphthalimide/phthalimide conjugates were synthesized by employing $\mathrm{Cu}^{\mathrm{I}}$ complex. This protocol involved
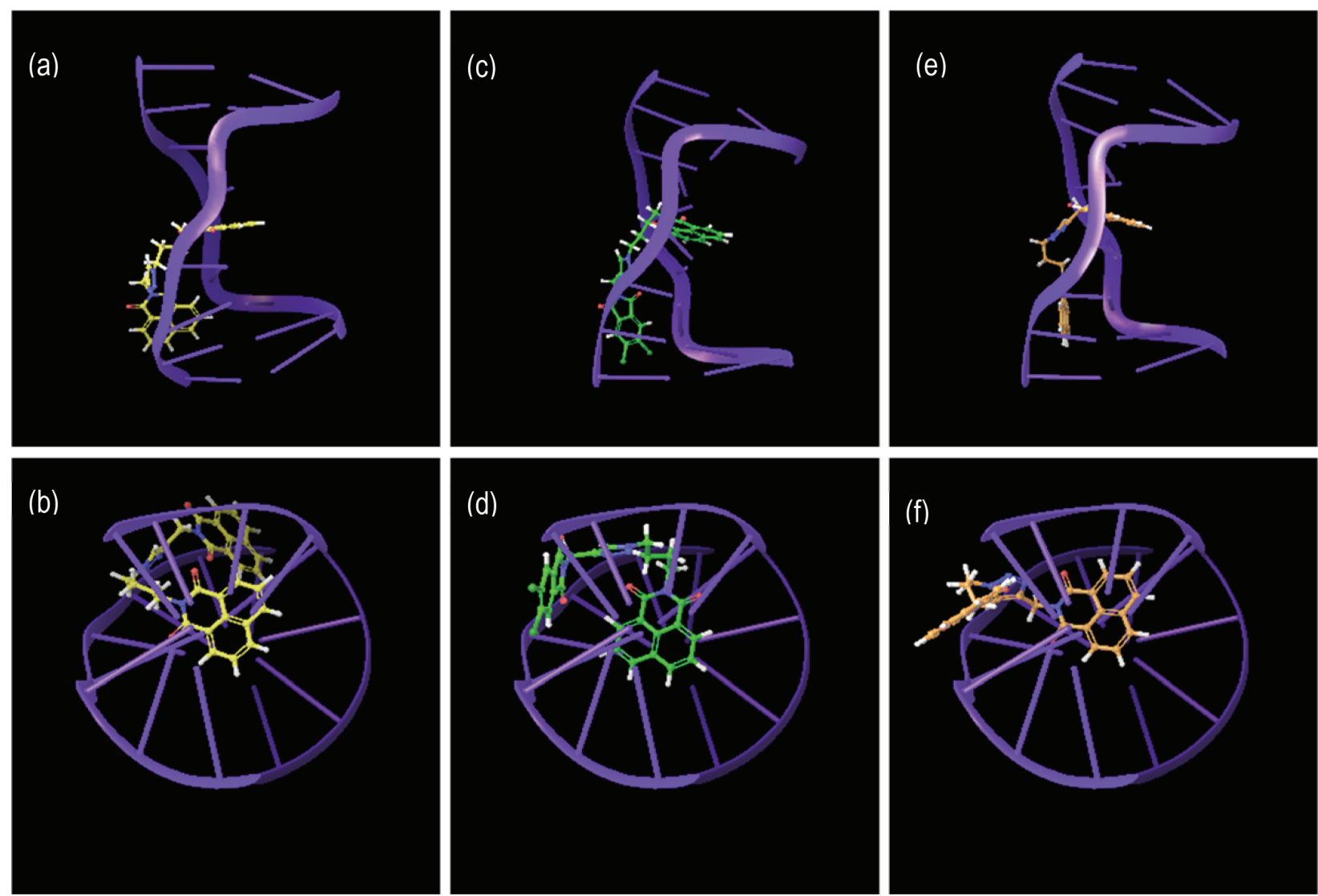

Figure 5. Side view (a) and top view (b) of $\mathbf{6 c}$; side view (c) and top view (d) of $\mathbf{6 d}$; side view (e) and top view (f) of $\mathbf{6 p}$, interaction with duplex DNA. DNA is represented as ribbon in blue color and compounds $\mathbf{6 c}, \mathbf{6 d}$ and $\mathbf{6 p}$ are represented in yellow, green and orange color, respectively. 
three component 1,3-dipolar cycloaddition of alkyl/ benzyl bromides, sodium azide and alkynes. The synthesized compounds were evaluated for their in vitro cytotoxic potential against lung (A549), prostate (PC-3), breast (MCF-7) and cervical cancer (HeLa) cell lines. Compound $\mathbf{6 c}$ displayed $\mathrm{IC}_{50}$ of $7.6 \pm 0.78 \mu \mathrm{M}$ against A549 lung cancer cells. Compound $\mathbf{6 c}$ also caused the death of cancer cells and induced apoptosis in concentration dependent manner as observed from DAPI and AO/EB staining. Further, relative viscosity studies indicated that increase in concentration of compounds $\mathbf{6 c}, \mathbf{6 d}$ and $\mathbf{6 p}$ proportionally enhanced viscosity suggesting that these compounds binds to DNA by intercalation. Molecular docking studies also supported the DNA interaction of these compounds. Overall, the current study established that these derivatives have the potential to be advanced as DNA interactive agents for the treatment of lung cancer.

\section{Supplementary Information}

Spectroscopic data and ${ }^{1} \mathrm{H}$ and ${ }^{13} \mathrm{C}$ NMR spectra of $\mathbf{6 a - x}$ and $7 \mathbf{a}-\mathbf{c}$ are available free of charge at http://jbcs.sbq.org.br as PDF file.

\section{Acknowledgments}

We are thankful to DoP, Ministry of Chemicals \& Fertilizers, Government of India, New Delhi, for the award of NIPER fellowship. Dr N. Shankaraiah is thankful to SERB, DST, Government of India for the start-up grant (YSS-2015-001709). Dr Santos thanks FONDECYT (1180084) and PIEI-Utalca (Qui-Bio) for supporting research activities.

\section{References}

1. Stewart, B.; Wild, C. P.; World Cancer Report 2014; WHO Press: Geneva, 2015.

2. Mallath, M. K.; Taylor, D. G.; Badwe, R. A.; Rath, G. K.; Shanta, V.; Pramesh, C.; Digumarti, R.; Sebastian, P.; Borthakur, B. B.; Kalwar, A.; Lancet Oncol. 2014, 15, e205.

3. Rashid, M.; Husain, A.; Mishra, R.; Eur. J. Med. Chem. 2012, 54,855 .

4. Nekkanti, S.; Tokala, R.; Shankaraiah, N.; Curr. Med. Chem. 2017, 24, 2887.

5. Jones, G. B.; Mathews, J. E.; Tetrahedron Lett. 1997, 53, 14599; Shankaraiah, N.; Sharma, P.; Pedapati, S.; Nekkanti, S.; Srinivasulu, V.; Kumar, N. P.; Kamal, A.; Lett. Drug Des. Discovery 2016, 13, 335.

6. Kamal, A.; Bolla, N. R.; Srikanth, P. S.; Srivastava, A. K.; Expert Opin. Ther. Pat. 2013, 23, 299.
7. Brana, M. F.; Cacho, M.; Gradillas, A.; Pascual-Teresa, B.; Ramos, A.; Curr. Pharm. Des. 2001, 7, 1745.

8. Andersson, B. S.; Beran, M.; Bakic, M.; Silberman, L. E.; Newman, R. A.; Zwelling, L. A.; Cancer. Res. 1987, 47, 1040.

9. Ratain, M.; Mick, R.; Berezin, F.; Janisch, L.; Schilsky, R. L.; Vogelzang, N. J.; Lane, L. B.; Cancer Res. 1993, 53, 2304.

10. Chen, Z.; Liang, X.; Zhang, H.; Xie, H.; Liu, J.; Xu, Y.; Zhu, W.; Wang, Y.; Wang, X.; Tan, S.; Kuang, D.; Quian, X.; J. Med. Chem. 2010, 53, 2589.

11. Cholody, W. M.; Kosakowska-Cholody, T.; Hollingshead, M. G.; Hariprakasha, H. K.; Michejda, C. J.; J. Med. Chem. 2005, $48,4474$.

12. Kamal, A.; Ramu, R.; Tekumalla, V.; Ramesh Khanna, G. B.; Barkume, M. S.; Juvekar, A. S.; Zingde, S. M.; Bioorg. Med. Chem. 2008, 16, 7218.

13. Brana, M. F.; Castellano, J. M.; Moran, M.; Perez de Vega, M. J.; Romerdahl, C. R.; Quian, X.-D.; Bousquet, P.; Emling, F.; Schlick, E.; Keilhauer, G.; Anti-Cancer Drug Des. 1993, 8, 257; Wilson, W. D.; Keel, R. A.; Jones, R. L.; Mosher, C. W.; Nucleic Acids Res. 1982, 10, 4093.

14. Leng, F.; Priebe, W.; Chaires, J. B.; Biochemistry 1998, 37, 1743.

15. Li, X.; Lin, Y.; Yuan, Y.; Liu, K.; Qian, X.; Tetrahedron 2011, 67, 2299; Wang, X. L.; Wan, K.; Zhou, C. H.; Eur. J. Med. Chem. 2010, 45, 4631.

16. Sing, P.; Sharma, P.; Anand, A.; Bedi, P. M. S.; Kaur, T.; Saxena, A. K.; Kumar, V.; Eur. J. Med. Chem. 2012, 55, 455; He, R.; Chen, Y.; Chen, Y.; Ougolkov, A. V.; Zhang, J. S.; Savoy, D. N.; Billadeau, D. D.; Kozikowski, A. P.; J. Med. Chem. 2010, 53, 1347; Thomas, K. D.; Adhikari, A. V.; Chowdhury, I. H.; Sumesh, E.; Pal, N. K.; Eur. J. Med. Chem. 2011, 46, 2503; Santos, J. O.; Pereira, G. R.; Brandão, G. C.; Borgati, T. F.; Arantes, L. M.; de Paula, R. C.; Soares, L. F.; do Nascimento, M. F. A.; Ferreira, M. R. C.; Taranto, A. G.; Varotti, F. P.; de Oliveira, A. B.; J. Braz. Chem. Soc. 2016, 3, 551; Cassamale, T. B.; Costa, E. C.; Carvalho, D. B.; Cassemiro, N. S.; Tomazela, C. C.; Marques, M. C. S.; Ojeda, M.; Matos, M. F. C.; Albuquerque, S.; Arruda, C. C. P.; Baroni, A. C. M.; J. Braz. Chem. Soc. 2016, 7, 1217; da Silva Junior, E. N.; Jardim, G. A. M.; Menna-Barreto, R. F. S.; de Castro, S. L.; J. Braz. Chem. Soc. 2014, 10, 1780.

17. Kamal, A.; Shankaraiah, N.; Devaiah, V.; Reddy, K. L.; Juvekar, A.; Sen, S.; Kurian, N.; Zingde, S.; Bioorg. Med. Chem. Lett. 2008, 18, 1468; Isobe, H.; Fujino, T.; Yamazaki, N.; Niekowski, M. G.; Nakamura, E.; Org. Lett. 2008, 10, 3729.

18. Shankaraiah, N.; Jadala, C.; Nekkanti, S.; Senwar, K. R.; Nagesh, N.; Shrivastava, S.; Naidu, V. G. M.; Satish, M.; Kamal, A.; Bioorg. Chem. 2016, 64, 42; Kumar, N. P.; Nekkanti, S.; Kumari, S. S.; Sharma, P.; Shankaraiah, N.; Bioorg. Med. Chem. Lett. 2017, 27, 2369.

19. Li, X.; Lin, Y.; Yuan, Y.; Liu, K.; Quian, X.; Tetrahedron 2011 , 67, 2299. 
20. Gil, M. V.; Arevaloa, M. J.; Lopez, O.; Synthesis 2007, 11, 1589.

21. Scriven, E. F. V.; Turnbull, K.; Chem. Rev. 1988, 88, 297; Silva, B. N. M.; Silva, B. V.; Silva, F. C.; Gonzaga, D. T. G.; Ferreira, V. F.; Pinto, A. C.; J. Braz. Chem. Soc. 2013, 24, 179.

22. Sharma, P.; Kumar, N. P.; Senwar, K. R.; Forero-Doria, O.; Nachtigall, F. M.; Santos, L. S.; Shankaraiah, N.; J. Braz. Chem. Soc. 2017, 28, 589.

23. Kamal, A.; Prabhakar, S.; Ramaiah, M. J.; Reddy, P. V.; Reddy, Ch. R.; Mallareddy, A.; Shankaraiah, N.; Reddy, T. L. N.; Pushpavalli, S. N. C. V. L.; Bhadra, M. P.; Eur. J. Med. Chem. 2011, 46, 3820.

24. Nekkanti, S.; Veeramani, K.; Kumari, S. S.; Tokala, R.; Shankaraiah, N.; RSC Adv. 2016, 6, 103556.
25. Sharma, P.; Senwar, K. R.; Jeengar, M. K.; Reddy, T. S.; Naidu, V. G. M.; Kamal, A.; Shankaraiah, N.; Eur. J. Med. Chem. 2015, 104, 11.

26. Tarnowski, B. I.; Spinale, F. G.; Nicholson, J. H.; Biotech. Histochem. 1991, 66, 297.

27. Sharma, P.; Thummuri, D.; Reddy, T. S.; Senwar, K. R.; Naidu, V. G. M.; Srinivasulu, G.; Bharghava, S. K.; Shankaraiah, N.; Eur. J. Med. Chem. 2016, 122, 584.

28. Shinomiya, M.; Chu, W.; Carlson, R. G.; Weaver, R. F.; Takusagaea, F.; Biochemistry 1995, 34, 8481.

29. Schrödinger Suite 2017-1; Schrödinger, LLC: New York, 2017.

Submitted: March 23, 2018

Published online: June 11, 2018 